\title{
Relato, pasado y modernidad: El ciclo festivo de Santiago Apóstol en Río Grande (Atacama, Chile)
}

\author{
Jaime Álvarez G. \\ Natalia Hamilton S.
}

\section{RESUMEN}

A partir de una observación participante, el análisis de fuentes y la comparación de relatos sobre la fiesta de Santiago Apóstol en la localidad de Río Grande, Región de Antofagasta, Chile, el presente artículo explora los cambios y continuidades que pueden identificarse en diversos ritos de esta comunidad andina del norte chileno. Tomando en cuenta una diversidad de relatos sobre las fiestas que giran en torno a la devoción al apóstol Santiago, se propone la existencia de un «ciclo festivo» que dura aproximadamente una semana. Además, se reconocen importantes hitos que hablan de la continuidad de la tradición, y de transformaciones que se producen a lo largo del tiempo, las que pueden atribuirse al avance de la modernidad dentro de la comunidad riograndeña. 
Palabras clave: Devoción, Santiago Apóstol, Norte Grande, relatos, modernidad, pasado

\begin{abstract}
Through participant observation, analysis of sources and comparing stories about the festivity of St. James in the village of Rio Grande, Antofagasta Region, Chile, this article explores the changes and continuities that can be identified in various rites of this Andean community of northern Chile. Considering diverse stories that comprehend different celebrations that are involved in the devotion to the Apostle James, we propose the existence of a "festive cycle", which lasts around a week. In addition, relevant milestones are recognized so to expose the continuity of tradition, and changes that occur over time, which can be attributed to the advance of modernity within the community of Río Grande.
\end{abstract}

KeYwords: Devotion, St. James, northern Chile, stories, modernity, past

\title{
1. INTRODUCCIÓN
}

Definir conceptualmente QUÉ ES UN RELATO no es tarea fácil. Diferenciarlo de la narración ha sido el primer desafío con el que nos hemos encontrado a lo largo de la elaboración de este artículo. Sin embargo, el relato como acto de ordenar hechos en un determinado marco temporal es algo que precede a la utilización de este por otras disciplinas como la Historia. En efecto, encontramos que el relato ya es utilizado para contar las hazañas del semidios Gilgamesh, en la civilización sumeria. Homero hará lo propio, relatando el retorno de Odiseo a Ítaca. Es decir, el relato como herramienta de registro es algo con lo que el ser humano se ha relacionado desde hace mucho tiempo.

El relato nace de la necesidad de anotar la experiencia humana, que puede ser personal o compartida, pero donde lo importante 
es dejar registro, que no se pierda la dimensión experiencial en el tiempo, ganándole a la inmediatez del olvido que podría cambiar hechos o introducir una cuota de subjetividad o inexactitud. Por tal razón, el relato se convierte en una fuente especial de la historia al ser registro del paso del tiempo o de un determinado periodo temporal en la vida del ser humano. Se trata de una fuente eminentemente subjetiva, al manifestar observaciones o recuerdos de un relator determinado, pero que, sin embargo, permite visualizar atmósferas, lugares, personajes, situaciones, acontecimientos, fechas, apreciaciones sobre la otredad, entre otros. En este caso buscamos acercarnos a través de diferentes relatos al «ciclo festivo» de la localidad de Santiago de Río Grande (o Río Grande), pueblo de ochenta habitantes (INE 2002) que pertenece a la comuna de San Pedro de Atacama, ubicada en la Provincia de El Loa, Región de Antofagasta, Chile. Hemos llamado «ciclo festivo» a un espacio temporal de aproximadamente una semana que comienza hacia el 24 de julio con la celebración de Santiago Aurora o Santiago El Menor, continuado con la fiesta al Patrono del pueblo, Santiago Apóstol, el 25 de julio, y la de Santa Ana, el 26, para finalizar con la noche de los abuelos y la limpieza de canales del sector y sus alrededores el viernes siguiente al 25 de julio.

Para acercarnos a este tiempo de fiesta, utilizaremos dos relatos que cuentan la celebración que se hace al patrono del pueblo, Santiago Apóstol: un primer relato corresponde al de los antropólogos George Serracino y Ana María Barón y data del año 1979. Los autores, que buscan mostrar al pueblo como un tambo atacameño, dan cuenta de la fiesta por medio de un texto descriptivo breve, donde esta es mencionada en forma ligera y se detallan solo dos ritos asociados a ella, el «baile de los cuartos» y el «teatro» (Serracino y Barón 1979: 3). Por otro lado, también disponemos de un relato extenso y meticuloso realizado por Domingo, Carolina y Paulina Gómez en el año 2013 (Gómez, Gómez y Gómez 2013: 118-121), en el que se reflejan los diversos signos, ritos y formas que pue- 
den apreciarse en la fiesta del Santo Patrono Santiago. Domingo Gómez, con quien pudimos establecer comunicación en el mes de octubre del año 2014, tiene estrechos vínculos con el Norte Grande desde 1958. Fue profesor de Ollagüe y Toconce, y visitó constantemente Río Grande mientras ejercía como docente, participando de la fiesta de Santiago Apóstol en variadas ocasiones. A esto sumaremos dos relatos que dicen tener relación con las ceremonias que cierran el ciclo festivo: el primero es sobre la íntima ceremonia llamada «la noche de los abuelos», relato publicado en 1981 por Reinaldo Lagos, Emilio Mendoza y Nolberto Ampuero. Este se inserta dentro de una investigación iniciada en 1968 sobre una segunda ceremonia que cierra el ciclo festivo de Santiago Apóstol y da inicio a las fiestas ceremoniales en honor a la naturaleza en la región, «la limpia de canales y acequias» del árido desierto; el relato de esta ceremonia es publicado en 1988 por los mismos autores en conjunto con Nora Hernández. El análisis de estos textos permitirá comprender estos ritos desde la experiencia de la propia comunidad, además de personas que han estado ligadas al pueblo durante tiempo importante, ya que sus autores, para lograr los relatos, realizaron entrevistas a riograndeños radicados en Chuquicamata y Calama, y contaron además con la participación activa de un cultor oriundo de Río Grande, Emilio Mendoza Cruz (Lagos, Mendoza, Ampuero y Hernández 1988: 44).

¿Qué novedades representa la utilización de relatos para analizar y comprender el «ciclo festivo» propuesto? Pretendemos explorar y deshilvanar la composición de los relatos encontrados para comprender cómo estos pueden ser una fuente que, más allá de su propia dimensión testimonial, puedan representar documentos que entregan posibilidades de interpretación histórica y conocimiento antropológico. ¿Es posible acceder al conocimiento del hombre por medio de un relato? ¿Son los relatos una herramienta adecuada para la construcción del conocimiento histórico? Frente a esto, hemos elegido el análisis y comparación de los relatos para acercarnos a las 
festividades de Río Grande, sumándole a ellos la propia experiencia de observación participativa realizada en la fiesta de Santiago Apóstol en el mes de julio del año 2014. Buscamos comprender cómo cada relato expresa el significado que cada relator le otorga a una determinada experiencia vivida, formando de este modo un complejo entramado de realidades que son reflejo de la diversidad presente en la realidad del ciclo festivo y de la cual fuimos testigos: gestos, significados, rituales, ceremonias, entre otras cosas, marcan la pauta de un ciclo polifónico que intentaremos abordar a través de los relatos.

Otro aspecto importante a considerar es que el relato es escrito en un determinado contexto: espacio y tiempo confluyen en la elaboración de un texto que relata algo, lo que podría arrojar más antecedentes y agregar complejidades al momento de trabajar con esta fuente. Ante esta arista, debe considerarse al relato no sólo como parte de un ciclo festivo relacionado con la fiesta de Santiago Apóstol, sino como unificador de distintas experiencias (Ricoeur 2005) y, con ello, herramienta para crear amalgamas de experiencias, vivencias, cambios y continuidades del ser humano. Las fiestas, los bailes y la música incesantes, el sacrificio matinal de un llamo, la llegada de personas desde otras localidades, el aumento de la población flotante y otros fenómenos no tendrían significado coherente si no estuvieran unidos bajo un mismo relato, que, en este caso, es la celebración al santo patrono de la localidad en cuestión. Comprender esta incesante mezcla de acontecimientos unidos por el tiempo será fundamental para comprender por qué el relato aúna lo distinto, pero contiene en sí mismo los diversos componentes que terminan por configurar lo que Mijaíl Bajtín llamó una realidad «polifónica» (Bajtín 1993: 33). En efecto, en su análisis sobre la novela de Dostoievski, el filósofo ruso señala que lo novedoso que presenta el autor de novelas como Crimen y Castigo es una autonomía de los sujetos, en la que por cada hecho u objeto hay una multiplicidad de voces, puntos de vista y conciencias, que actúan en for- 
ma independiente pero que conforman un diálogo, una «polifonía» (Bajtín 1993: 37). En términos musicales, una polifonía es la suma de diversas melodías y voces que actúan simultáneamente, lo que, muy en sintonía con lo propuesto anteriormente por Ricoeur, nos da a entender cómo un relato puede ser efectivamente polifónico. Bajtín ahondará en otras implicancias de esta «polifonía», como que no puede haber una verdad determinada por un solo relato, sino que esta es conformada también por una conjunción de estos, que dialogan los unos con los otros.

La metodología utilizada para analizar los relatos está dividida en tres partes fundamentales: en primer lugar, se hizo necesaria la recopilación de antecedentes sobre el sitio que fue nuestro objeto de estudio. Consideramos que no puede analizarse su ciclo festivo si no es en relación con su contexto, por lo que averiguar sobre la localidad de Río Grande fue una tarea imperativa a la hora de abordar la celebración de su santo patrono y las festividades asociadas. En ello se han utilizado principalmente fuentes escritas existentes sobre el poblado andino, atestiguándose una carencia en antecedentes relativos al periodo prehispánico y colonial. Dentro de esta búsqueda documental, el hallazgo de los cuatro relatos mencionados anteriormente — Santiago de Río Grande, un tambo atacameño (Serracino y Barón 1979); Fiestas y ceremonias tradicionales andinas. Región de Antofagasta (Gómez, Gómez y Gómez 2013); La noche de los abuelos en Santiago de Rio Grande (Lagos, Mendoza y Ampuero 1982), y La limpia de canales y acequias de Santiago de Río Grande (Lagos et ál. 1988) — fueron la piedra angular para plantear un problema de investigación: el relato más antiguo del que disponemos data de fines de los años setenta, sin duda, un vacío en fuentes históricas que narren el ciclo festivo. En segundo lugar, y retornando con ello a la explicación metodológica de lo realizado, consideramos importante señalar que la observación participativa como método antropológico de investigación es parte fundamental de este trabajo. Principalmente porque asistir en tiempo de fiesta a la localidad de Río Grande permitió realizar 
un abundante trabajo de campo sobre la festividad y la transformación de lo cotidiano que ella implica. La complementariedad de nuestras narraciones de la fiesta será vital para analizar los otros relatos, puesto que la vivencia en primera persona de algunos rituales de este ciclo festivo permitirá cotejar la información obtenida con la propia, enriqueciendo de este modo lo visto. Finalmente, será la polifonía de los relatos, en conjunto con los antecedentes del poblado y la experiencia personal de participar y observar los ritos durante el tiempo de fiesta, los que dialoguen y se conjuguen para dar pie al análisis e interpretación de los cambios y continuidades del ciclo festivo de Río Grande, tercera parte y última de lo que aquí se presenta.

Para finalizar, viene bien preguntarse en qué marcos disciplinares se encuentra el presente trabajo. El uso de fuentes, las consideraciones sobre el marco temporal y las interpretaciones que realizaremos hablan de una tarea relacionada principalmente con la disciplina histórica. Sin embargo, observar y participar de la fiesta, anotando y analizando lo visto, lo dicho y lo que realmente es, obedece a un trabajo esencialmente etnográfico que, al investigar el mundo del otro en el pasado y en el presente, se relaciona fuertemente con la etnohistoria. Por ello, se trata de un trabajo que combina distintas disciplinas y que viene a confirmar cómo la riqueza de la interdisciplinariedad permite comprender al hombre de una mejor manera.

\section{Una estancia de alfalfa y Chacras: antecedentes de San- TIAgo DE Río Grande}

Será a partir de la Guerra del Pacífico, momento en que estas tierras cambian de jurisdicción boliviana a chilena, que aparecen las primeras luces sobre el pueblo atacameño. $Y$ es que desde tiempos anteriores sabemos que el espacio geográfico en donde se ubica Río Grande fue parte del Kollasuyu, el mayor y más austral de los suyus del 
Imperio incaico. Para la llegada de los españoles, fue dependiente del partido de Atacama, el que, a partir de 1776, pasa a ser parte del Virreinato del Río de la Plata con dos curatos o doctrinas, divisiones administrativas de carácter eclesiástico, pero también útiles para efectos civiles: Atacama La Alta o La Oriental y Atacama La Baja u Occidental (Cañete y Domínguez 1939: 245). Lamentablemente no ha sido posible encontrar en las fuentes escritas referencias a Río Grande como perteneciente al partido de Atacama, sin embargo, por su ubicación, se asume su vinculación al curato de Atacama La Alta. José María Cassasas Cantó ha reforzado esta idea al describir las iglesias y capillas de la zona en el periodo colonial y mencionar a la iglesia de Río Grande, junto a las cuales no se han encontrado mayores registros históricos, pero sí que están circunscritas bajo el mencionado curato (Cassasas Cantó 1974: 84). La falta de antecedentes será recurrente en los diversos autores que indagarán sobre Río Grande, y es que incluso los riograndeños aseguran que el libro de la iglesia está perdido desde 1973, en el cual se consignaba el encargo para obtener, desde España, una campana para la iglesia (Aldunate, Castro y Varela 2008: 104).

En el Boletín de la Guerra del Pacifico, que periódicamente informaba sobre dicha guerra, se narra la llamada escaramuza de Río Grande, que data del 10 de septiembre de 1879. Tropas chilenas y bolivianas se enfrentaron en las cercanías del caserío, el cual, según las descripciones, se encontraba vacío y con animales en sus inmediaciones (Fernández 1979: 387 y 571), probablemente debido a un abandono temporal producto de la escaramuza. Paralelo - y posteriormente - a la Guerra del Pacífico, diversos hombres de ciencia, exploradores y viajeros de fines del siglo XIX y principios del xx, recorrieron la zona revelando al poder central el desconocido «despoblado» y determinando qué se entenderá por aquel territorio denominado desierto de Atacama. En ese contexto, cargado de esfuerzos por aprehender, conquistar y humanizar el norte del país — realidad que bien grafica Manuel Vicuña (1995) en su obra 
La imagen del desierto de Atacama (XVI-XIX): Del espacio de la disuasión al territorio de los desafíos-, el ingeniero Alejandro Bertrand, jefe de la sección de cartas y planos de la Oficina Hidrográfica, emprendió la tarea de elaborar informes y mapas de los departamentos de Tacna, Arica y Tarapacá. En mula recorrió la región, y al llegar a Río Grande lo describió como una estancia de 23 hectáreas de alfalfa y chacras, donde vivían tres familias de indios atacameños y que distaba 50 kilómetros de San Bartolo (Bertrand 1885: 272). Uno de los principales legados de Bertrand fue el mapa del desierto de Atacama elaborado en el año 1884, en el que se señala a Río Grande junto a San Bartolo, Peñaliri, Artola y Ayaviri, zonas vinculadas con el pueblo en estudio (Bertrand 1885).

Durante el mismo periodo, miembros de la Comisión Exploradora del Desierto de Atacama — que comenzó en 1883 y concluyó en 1890 — describieron en detalle el paisaje, las condiciones geológicas y geográficas del lugar, y hablaron sobre un pequeño caserío sin habitantes para el momento de su llegada (San Román 1883: 446; Sundt 1909: 158). Por otro lado, a fines del siglo xIx, Francisco Solano Astaburuaga y Cienfuegos definió a Río Grande en su Diccionario Geográfico de la República de Chile, sin dar mayores detalles del poblado y sus habitantes (Solano Astaburuaga y Cienfuegos 1899: 667).

Entrando en el siglo xx, la aparición de Río Grande en las fuentes escritas aumenta considerablemente, pero tampoco es abundante. En 1907, la Oficina de Límites, con la Sección Topográfica y la Comisión Radicadora de Indígenas de la Inspección de Colonización, se unificaron bajo el nombre de Oficina de Mensura de Tierras. Su director, Luis Riso-Patrón, describió en uno de sus viajes a Río Grande como un caserío de 61 habitantes, diez casas y una capilla (Riso-Patrón 1910: 115, 1924: 771). Y en su Diario de viaje a las cordilleras de Antofagasta y Bolivia relató la entrada a Río Grande por un camino proveniente desde Machuca, haciendo mención de un carnaval al momento de su llegada: «Todo el mundo se emborra- 
chaba, enterrando el carnaval y no había persona con sus sentidos despejados, con quien poder hablar» (Riso-Patrón 1918: 175-176).

Ya en los años setenta, el etnógrafo Héctor Pumarino, quien estudió por alrededor de cuarenta años la zona andina de la Provincia de El Loa, describió al pueblo de Río Grande como uno de los antiguos ayllus atacameños. Además de la ubicación, clima y accesibilidad al pueblo, el autor hizo referencia a sus 135 habitantes, quienes cultivaban maíz, trigo y hortalizas, y tenían ganadería lanar de llamas y ovejas, abundante pesca de trucha y explotación de yareta. En relación con las festividades religiosas, hizo alusión a la celebración de Santiago Apóstol, el 25 de julio, y a san José Obrero, destacando además al conjunto instrumental de sicus, formado por hijos del pueblo, que, según el autor, tenían una buena ganada fama regional. Pumarino también publicó una fotografía de la iglesia de Río Grande, postulando que su construcción data de 1895. Por último, es novedosa la sugerencia del etnógrafo hacia el potencial turístico del lugar (Pumarino 1978: 167-168).

Lagos, Mendoza, Ampuero y Hernández (1997), autores del relato sobre la limpia de canales y acequias en Río Grande, publicaron la transcripción de una entrevista realizada al riograndeño Emilio Mendoza en el año 1983. En ella, Mendoza afirmaba que, debido a su condición geográfica, Río Grande aún mantenía la «autenticidad» o «no contaminación» de sus costumbres. Destacaba la relación de los pobladores con la tierra, la cual consistía principalmente en la idea de ser un ocupante temporal de ella. De esta concepción nacía la práctica del floreo del ganado, que tenía como fin el pago a la tierra por el consumo de ella. La práctica del enfloramiento también guardaba relación con los patrones del pueblo, pues el pastor velaba a los santos que se relacionaban con su propio ganado, de hecho, Santiago Apóstol estaba vinculado a los caballos (Lagos et ál. 1997: 113). Por último, nos encontramos con un valioso glosario de términos locales relacionados con el ganado, pero también con los tiempos de fiesta y el cotidiano. 
En 1979, George Serracino y Ana María Barón serán los primeros — de lo encontrado hasta ahora - que realicen un relato escrito de la Fiesta de San Santiago de Río Grande. Aquel relato marcará un punto de inflexión en nuestra investigación, siendo analizado junto con los otros relatos del ciclo festivo riograndeño. Serracino y Barón describieron al pueblo dividido en cuatro sectores: el sector de la quebrada abajo, el sector de Peñaliri, el de San Juan y el centro, que sería el pueblo propiamente tal con solo tres familias residentes (Serracino y Barón 1979: 8). Sobre los antecedentes históricos de Río Grande, los antropólogos encontraron una página vacía, postulando al cementerio como fuente, siendo la sepultura más antigua la de Apolinar Salva, que data de 1905. Además, los autores hacen referencia al relato oral de los riograndeños, quienes aseguraban que otros entierros se hacían en partes de la quebrada sin ninguna ubicación especial (Serracino y Barón 1979: 5). Victoria Castro analizó los apellidos de las personas que yacen en el cementerio, sosteniendo que estos, de origen indígena y español, son frecuentes de encontrar en el altiplano de Iquique y de Lípez (sur de Bolivia). En relación a los nombres de las sepulturas del cementerio de Machuca, la autora plantea la posibilidad de que este último haya estado unido a Río Grande, San Juan y Peñaliri (Castro, Romo, Villagrán y Latorre 1999: 324-325).

Original es la tesis de Serracino y Barón referente a Río Grande como un tambo atacameño, condición justificada por ser un lugar de paso y descanso de los arrieros de toros provenientes de Argentina hacia Calama y de los peregrinos de San Pedro de Atacama y Toconao — que cada 8 de septiembre se dirigen a Ayquina para la fiesta de la Virgen de Guadalupe_-; también por haber sido refugio en la conquista española para los lugareños que no querían cambiar sus tradiciones. Para los autores, Río Grande se ubica estratégicamente entre Turi y San Pedro de Atacama, dos centros arqueológicos, y entre Caspana, San Pedro de Atacama y Chiu Chiu; considerando la costumbre inca y preinca de construir aproximada- 
mente una casa cada 17 kilómetros. De todas formas, se justificaría su función como tambo solo para el traslado a pie, atenuándose luego de la construcción del nuevo camino hacia San Pedro de Atacama (Serracino y Barón 1979: 5-10).

En correlato con la evangelización de la cuenca de Atacama, también se sustentará el postulado de Río Grande como tambo al ser parte del entorno en el que se levantaron iglesias que requerían de campañas estables de evangelización (Núñez, González y Galeno 2010: 20). Con respecto a la fecha de construcción de la iglesia de Río Grande, los enunciados son divergentes. Hasta el momento, solamente hemos mencionado la indicada por Héctor Pumarino, quien establece que data de 1895. Por el contrario, los arquitectos de la Universidad Católica del Norte, Larry Games y Cristián Games, señalaron tres fechas posibles de construcción: 1650, 1890 y 1963. Sin profundizar en cada una de ellas, sugirieron que su construcción original data del siglo XVIII (Games y Games 2009: 167). La primera fecha postulada por los arquitectos coincide con la sugerida por Núñez, González y Galeno (2010: 20-28), posiblemente al considerar a Río Grande como tambo en las rutas caravaneras entre San Pedro de Atacama y Caspana en el periodo de evangelización. Lamentablemente no existen mayores referencias al año en que se construyó la iglesia, y, considerando el extravío de los papeles parroquiales en 1973, la tarea se ve compleja.

Finalmente, será interesante y poco explorada la vinculación de Río Grande a la industria minera, por su cercanía a la mina prehispánica San Bartolo, la que, según los lugareños, habría sido explotada hasta alrededor de 1930, influyendo en las actividades de los riograndeños, quienes habrían trabajado en labores de abastecimiento de la mina, como arrieros y/o abastecedores de talaje o productos agrícolas. 


\section{El «CICLO FESTIVO»}

Hablar del «ciclo festivo» propuesto implica delimitar o contextualizar dicho lapso temporal para caracterizarlo y comprenderlo a cabalidad. Para ello, es fundamental considerar cómo la tradición riograndeña ha delimitado este periodo a lo largo de su historia. De acuerdo a lo propuesto por Lagos, Mendoza y Ampuero (1982: 248274), tradicionalmente, en Río Grande comienzan las celebraciones con el día de Santiago Aurora, el 24 de julio. El 25, como corresponde a la festividad fijada en el calendario para ese día, se realizan las ceremonias para celebrar a Santiago Apóstol, patrono del pueblo. El 26 de julio se celebra a santa Ana, última santa católica del ciclo festivo. Los mismos autores señalan que la tradición del pueblo mandaba que una semana después de la celebración al patrono de Río Grande se lleve a cabo la noche de los abuelos y la limpieza de canales y acequias: «Teníamos antecedentes sobre una reunión de tipo privado que realizaban los riograndeños en la noche anterior a la faena misma y que era imposible que se nos permitiera participar de ésta» (Lagos, Mendoza y Ampuero 1982: 248).

En el caso del año 2014, el programa estipulaba que se daba inicio al periodo festivo el día martes 22 de julio junto a una ceremonia de los abuelos con toda la comunidad riograndeña, y un posterior inciensamiento de las zampoñas, instrumento vital para el buen desarrollo de los cánticos y bailes que se realizarán a lo largo de toda la semana. Luego, a las 5:00 de la madrugada del 23 de julio, entran los bailes religiosos al pueblo de acuerdo al orden en que llegaron. A las 7:00 am se realiza la ceremonia del alba encabezada por los alféreces del año en curso. Durante la tarde, las celebraciones comienzan a partir de las 15:00 y especialmente desde las 16:00, cuando se produce la primera ceremonia en honor al santo que se está celebrando, en este caso, a Santiago Aurora. En la ceremonia de la cera se ofrecen diversas tinkas al santo, fundamentalmente vino y hojas de coca, aunque también 
puede haber alimentos. Esto se realiza hasta las 20:00, momento en el que comienza la víspera del santo y se ilumina la iglesia del pueblo para celebrarlo en su día que se aproxima. A la mañana siguiente, 24 de julio, comienzan las actividades a las 4:00 am con un alba ofrecida por los alféreces, seguida por el sacrificio de un llamo blanco a las 7:00 am, que no se realiza —al menos no explícitamente- en honor al santo. Aparentemente se trata de una ceremonia anexa, que se realiza en el día de Santiago Aurora pero que no tiene relación directa con él. A las 10:00 se realiza una misa y posteriormente una procesión.

En general, el esquema de un día festivo del ciclo que se propone obedece a los marcos mencionados anteriormente: salvo algunas modificaciones, para cada día hay un alba ofrecida por los alféreces, una boda (almuerzo), una cera (ofrenda) y una víspera que se realiza en la iglesia del pueblo. Puede observarse que los ritos ofrecidos a Santiago Apóstol a partir del 24 de julio en la tarde son más que los que se hacen al resto de los santos: además de la cera, la boda y la víspera, se realiza una misa, se saluda al santo con bailes religiosos y se iza el pabellón patrio. Además, se realiza una procesión y baile alrededor del pueblo con todos los miembros de la comunidad, que incluirá por primera vez el baile de los cuartos, en el que miembros de Río Grande danzan por las calles del pueblo llevando la mitad de un cordero entre dos personas, siempre mirando al santo patrono que preside la ceremonia.

Observaremos que el ciclo festivo tiene un marco tradicional para llevarse a cabo, probablemente heredado de la tradición que el pueblo ha seguido durante siglos. En base a ello es que la limpieza de acequias y canales debía realizarse una semana después de la fiesta de Santiago Apóstol, y la víspera anterior, la noche de los abuelos. Sin embargo, el programa del ciclo festivo del año 2014 establecía ciertos cambios que rompían con esa tradición. Por de pronto, la limpieza de canales y acequias ya no se realiza «el primer sábado inmediato al 25 de Julio, día del Patrono del pueblo, 
San Santiago, ocupando para ello todo el día» (Lagos, Mendoza y Ampuero 1982: 248), sino un lunes, y a la tradicional noche de los abuelos se agregó otra ceremonia de similares características un día jueves. Lo anterior permitió plantear el ya conocido binomio de la historia que evidencia los cambios y las continuidades de determinados hechos o sucesos históricos. En ese sentido, el análisis de los relatos que disponemos ha permitido establecer dos fases en las que se desarrollará este artículo: una primera, donde se abordará aquello que tiene que ver con la continuidad y la memoria del ciclo festivo y que, por lo tanto, se ha mantenido intacto durante el paso de los años. Una segunda parte busca hipotetizar sobre los cambios que se han producido y cómo el avance de la modernidad ha influenciado en las transformaciones que se han realizado en el marco tradicional del ciclo festivo.

Continuidad y memoria. Por medio del análisis de los relatos disponibles se pueden establecer ciertas continuidades que están relacionadas principalmente con los signos y formas en que se realizan las ceremonias enmarcadas en el ciclo festivo. Es por ello que, basándose en este análisis, se pueden establecer tres aspectos que continúan sin modificación a lo largo del tiempo y que parecen ser los marcos estructurales de la ritualidad riograndeña, inmodificables desde tiempos ancestrales: el diálogo, los ritos ceremoniales y los signos que comunican a las personas con las divinidades a las que se les rinde culto.

El diálogo existente en las distintas ceremonias puede reconocerse, en primer lugar, en el respeto existente hacia la Pachamama o Madre Tierra. La celebración no es unilateral, sino que puede establecerse una bidireccionalidad en la que hombres y divinidades interactúan por medio de diferentes signos. Uno de ellos es el permiso que se le pide a la tierra para realizar las ceremonias, rito que puede identificarse en el relato más antiguo, que data de fines de la década de los 60, y el más reciente que está fechado en el año 2013. 
No sólo se trata de una ofrenda o diálogo unilateral, sino que se espera una reacción determinada de la Pachamama, a la que se le atribuye la posibilidad de comunicación entre los distintos espíritus que la componen. Así, el relato sobre la «Noche de los abuelos» nos da luces sobre el rito más importante, antes de comenzar cualquier otro hito relacionado con esta importante fase del ciclo festivo:

En el salón principal de la Casa Comunal, casa del pueblo, también llamada «Ramada», se reúnen los pobladores y visitas (hijos del pueblo o visitas de ellos) para pedir personalmente y en presencia de toda la comunidad, el permiso respectivo a la Pacha Mama o Santa Madre Tierra, para que puedan realizar en el día siguiente el trabajo de la limpia de acequias y canales. Esta petición de permiso sirve además para alertar a los «Puricamanes», espíritus del agua, para que ellos comuniquen a su vez, a los espíritus del viento, volcanes, potreros, canales, lluvia, caminos y de los animales a fin de que nada ni nadie cree problemas obstaculizantes naturales o discordias entre los participantes [...].

No sólo se le atribuyen distintas almas a la Pachamama, sino que también esta podría «irritarse» en caso de que el permiso correspondiente no fuera solicitado de acuerdo a la tradición del pueblo, situación que se mantiene hasta la actualidad, según el relato de Domingo, Carolina y Paulina Gómez (2013: 118-121). Lo anterior incluye también a los antepasados, quienes son venerados y recordados en cada fiesta que se celebra. En el relato recién mencionado, además de la preocupación por la Pachamama, se agrega una fiesta para venerar a los ancestros, realizada el 22 de julio, día en el que se ofrecen tinkas en honor a ellos. Esta ceremonia es un diálogo con las almas de quienes los precedieron en la vida terrenal, pero dentro de ella hay un momento en que las ofrendas para los antepasados se depositan en la tierra en medio de la pampa. Además, la devoción por las almas de los ancestros marca constantemente la vida cotidiana de los lugareños mientras se encuentran en temporada festiva: cada vez que van a beber alguna bebida alcohólica, sobre todo si fue 
ofrecida en la cera, se vierte en el suelo un chorro para la Pachamama y un chorro para los abuelos. El relato de los Gómez evidencia esto cuando caracteriza la fiesta de los abuelos que se realiza justo al inicio del ciclo festivo:

Un poblador lleva vino, otro cerveza; todos ofrecen algo para la tinka. Entonces, el fabriquero, que es el encargado de la iglesia del pueblo, dice «vamos a tomar algo para comenzar la fiesta de San Santiago. Con permiso de los señores, que pasemos una fiesta bonita el 25 de julio; que nunca caigan heladas. Salud, y que nos ayuden». Pidiendo siempre, echan con la derecha poquito y hay que llenar el cántaro con coca, harina de maíz y harina de quínoa. La derecha es por los abuelos, por los más antiguos, las momias; y la izquierda por las almas de los muertos.

Otro momento importante del diálogo existente entre la $\mathrm{Pa}$ chamama y los hombres ocurre con las numerosas ofrendas que se realizan en los diversos ritos que componen el tiempo de fiesta. En ese sentido, pueden rescatarse algunas antiguas tradiciones que funcionan como conectores con la divinidad porque son ofrendas que se entregan directamente a las almas o a la Santa Madre Tierra. Por ejemplo, de acuerdo a lo observado en nuestro trabajo de campo, esto ocurre en el sacrificio del llamo blanco que se realiza el 24 de julio a las 7:00 de la mañana, cuando la comunidad reunida en la casa comunal sacrifica este animal frente a un altar de piedra y deposita la sangre en un agujero ubicado frente a este. Luego de que la sangre deja de escurrir, se tapa con tierra y lo mismo se hace con aquella sangre que se encuentra fuera del agujero. Después, el marido de la alférez procede a lanzar en las cuatro esquinas de la sede una mezcla de sangre, vino, harina de maíz y coca. Posteriormente, alrededor del altar monolítico, ambos comienzan a bailar una especie de trote en forma circular, que cada cierto rato cambia en la dirección contraria. A este baile se suma la comunidad completa y al mismo tiempo se ofrece a todos los presentes vino caliente. $\mathrm{La}$ ofrenda está hecha, corresponde ahora la celebración. 
Una dinámica similar a la anterior es relatada por Reinaldo Lagos y coautores en la noche de los abuelos, cuando, una vez que los cántaros llenos de ofrendas se vacían en la mitad de la pampa, se produce un periodo de silencio y constricción entre los riograndeños, momento en el cual pareciera que cada uno de los pobladores está haciendo su plegaria correspondiente. A su vez, con el retorno de quienes han ido a ofrecer cosas a la Pachamama, existe celebración y fiesta porque han vuelto bien, sanos y salvos y no han sido poseídos por algún alma. El rito ha sido completado con éxito, y se procede ahora la celebración:

Ya dentro de la ramada, los capitanes saludan con un «Buenas noches señoras y señores». Hacen sonar tres veces los putuputus [sic]. Los comuneros contestan el saludo con grandes muestras de felicidad, dándoles una bienvenida muy cariñosa y real contento $[\ldots]$ los capitanes demuestran un cambio total de expresión, desbordando alegría y como si nunca se hubiera reunido antes.

El relato de la limpia de canales ofrece, por otra parte, más información sobre esta estrecha relación entre los miembros de la comunidad de Río Grande y la Pachamama. De acuerdo a sus autores, la limpia de canales habla de una estrecha relación entre los hombres y su divinidad más importante, toda vez que se asimila la limpieza de estos acueductos con una limpia de las arterias de la Santa Madre Tierra. De ahí que los autores expliquen cómo se realizan distintas ofrendas, con importante presencia de hojas de coca, las que dejan circular por el agua (Lagos et ál. 1988: 53). De esta forma, no sólo se cierra un ciclo festivo, sino que se abre otro momento en la relación entre los hombres y la tierra, puesto que, al limpiar «las arterias» de la Pachamama, se vuelve a iniciar el ciclo por el cual están agradeciendo y pidiendo que les sea favorable. De alguna manera, con esta importante ceremonia termina el ciclo festivo que hemos propuesto en este trabajo, momento que ha permitido que hombres y mujeres del pueblo puedan realizar ofrendas 
y plegarias a ancestros y a la Pachamama, con el fin de devolver a esta lo que les ha dado.

También es importante mencionar la existencia de otros elementos que son parte de la continuidad del ciclo festivo en Río Grande, la mayoría relacionado a la estructura con la que se organiza la fiesta. En ese sentido, resulta sustantivo mencionar que los motivos de la fiesta se mantienen intactos, como también la preponderancia de la ofrenda para agradar a la Pachamama y a los santos católicos. En muchos de los relatos que hemos analizado, los ritos ceremoniales no han experimentado cambios en su contenido esencial y es a partir de ello que se puede establecer que el diálogo entre lo divino y lo terrenal es una permanencia a lo largo del tiempo, lo que se apoya en que la concatenación de las fiestas no cambia: el orden es cuidadosamente celado por los habitantes del pueblo, debiendo respetarse año a año la regla de celebrar primero a Santiago Aurora, luego a Santiago Apóstol y finalmente a santa Ana. En ese marco de celebración, donde se resalta lo eminentemente católico, los rituales que se encuentran día a día también son respetuosamente ordenados y llevados a cabo. Así, la cera, la boda y la víspera se pueden encontrar en cada día que se celebra a un santo católico, confirmando la potente imbricación entre tradiciones prehispánicas y ritos católicos, insertos bajo un mismo marco temporal de festividad. El respeto reverencial que se ha mencionado con anterioridad, y que tiene como principal figura a la Madre Tierra, también es una constante en los relatos encontrados. Así, por ejemplo, existen momentos en que se realizan oraciones católicas o misas que, aunque siendo minoritarias en comparación con las otras ritualidades, también son parte importante de los ritos que se configuran.

Las festividades ligadas al santo patrono Santiago Apóstol incluyen liturgias y misas, donde las personas participan con devoción, aunque, de acuerdo a lo observado en el trabajo de campo, son pocos los que participan del rito de la comunión, momento cúlmine de la celebración eucarística católica. Pese a que el foco de atención 
está puesto de forma eminente sobre la Madre Tierra, en la noche de los abuelos también existe un momento en que se reza al Padre, al Hijo y al Espíritu Santo, sin olvidar a la Virgen María. Sin embargo, lo verdaderamente importante es por qué se realiza esa oración, único momento católico de la noche: se pide por los ancestros y sus almas, además de tener presente a las almas que puedan estar perdidas. En consecuencia, reaparece en lo católico la fuerte conexión con los antepasados mencionada anteriormente:

A continuación habla el fabriquero expresando: «con su permiso señores capitanes Puricamanes, autoridades, acompañamiento, como ya vamos a entregar las voluntades, rezaremos tres Padre Nuestros, diez Ave María y un Gloria al Padre, por las ánimas benditas, para aquellas personas que han hecho las costumbres, para los que hicieron los cimientos de los canales y para aquellas almas perdidas».

Finalmente, resulta importante rescatar la continuidad de numerosos elementos rituales que se mantienen y que funcionan como verdaderas vías de conexión entre el mundo terrenal y el mundo divino. Aunque no aparecen en el programa, sería difícil entender cada celebración o ritual sin la presencia de la hoja de coca, a la que también llaman «Santa Madre» (Lagos, Mendoza y Ampuero 1982: 264). La presencia de las hojas de esta planta se encuentra a lo largo de todo el ciclo festivo, convirtiéndose en la ofrenda privilegiada de cualquier acto que incluya adorar a la Pachamama, a los santos católicos o simplemente hacer un gesto comunitario entre personas que comparten una misma tradición. Por otro lado, la música y los bailes son esenciales para una buena realización de este periodo de fiesta, puesto que acompañan la mayoría de los ritos y cumplen un rol trascendental en la procesión que se realiza con la figura de los santos Santiago Aurora y Santiago Apóstol el 25 de julio. Asociado a esto, la tinka como ofrenda es parte fundante de cualquier ceremonia: se trata del medio por el cual se establece un diálogo privilegiado con la Pachamama, a quien hay que agradecerle año a año para que siga 
cuidando la producción agrícola, las almas de los ancestros y la vida de quienes son hijos del pueblo. Dentro de estos mismos aspectos o medios de conexión con la divinidad puede encontrarse el llamado pujgio, orificio que se hace en la tierra y que representa el corazón de la Pachamama (Lagos, Mendoza y Ampuero 1982: 257). De ahí que cada vez que se hace una ofrenda, como la sangre del llamo blanco, esta sea depositada en un agujero y luego tapada con tierra.

La comprensión y existencia de estos elementos es trascendental para entender el ciclo festivo de la localidad de Río Grande. No sólo porque expresan la polifonía de símbolos y rituales que componen las distintas ceremonias, sino también porque hablan de cómo la tradición del mundo andino sigue viva pese a las transformaciones que se han producido por el avance de la modernidad. En el próximo apartado abordaremos algunos cambios que hemos podido detectar en el ciclo festivo, pero también hemos sido testigos de cómo la continuidad de la tradición, la memoria por los ancestros y sus almas, y el diálogo y respeto reverencial a la Pachamama y a los santos católicos son aspectos que han logrado mantenerse a lo largo del tiempo.

Cambios y modernidad. Al comparar los relatos sobre el ciclo festivo de Río Grande y al observar y participar de la festividad en el año 2014, nos encontramos con un primer indicio de cambio referente a la modificación de su estructura. Si tenemos en consideración que la concatenación de las ceremonias y ritos que incluye el tiempo de fiestas es celada rigurosamente por la comunidad, un cambio en su calendarización tradicional no debe ser minimizado. De igual manera, veremos cómo la presencia femenina en ciertos roles que eran exclusivamente masculinos y la llegada de la Iglesia Unida Pentecostal al poblado andino serán otros elementos que evidencien un tiempo festivo que muta, se adapta y cambia.

En base al relato de la limpia de acequias y canales (Lagos et ál. 1988), se consta que, en la víspera al trabajo comunitario, se lle- 
vaba a cabo la privada ceremonia ritual de la noche de los abuelos, la que estaba tradicionalmente establecida para el viernes siguiente a la fiesta de Santiago. Sin embargo, como observaremos en la programación del ciclo festivo del año 2014, cambia la tradicional calendarización de los días dispuestos para celebrar la noche de los abuelos y, por ende, la limpia de acequias y canales: se programa la «Convivencia de los abuelos por la limpia de canal» para el domingo 27 de julio, inmediatamente después de finalizar la fiesta dedicada a la última santa católica del ciclo, santa Ana (véase anexo 1). Al preguntarnos por qué en la actualidad la duración del ciclo festivo es menor en comparación con los primeros relatos, los cambios sociales y económicos vinculados al poblado andino serán las primeras señales para formular una respuesta y comprender de mejor manera la fiesta riograndeña.

Las primeras descripciones del poblado que detallábamos en párrafos anteriores nos sugieren una comunidad pequeña ligada a la agricultura, en la que se puede inferir que los tiempos festivos tenían estrecha relación con el ciclo agrícola y las estaciones del año.

De acuerdo con lo propuesto por Lagos et ál. (1988: 54), un primer cambio en la estructura tradicional de Río Grande data de 1966, año en que el trabajo de la limpia de canales y acequias, junto con otras actividades que concernían al bien común y que favorecían a todo el pueblo — tales como la construcción de iglesias, casa comunal, cementerio, campos deportivos, construcción y mantención de caminos - dejaron de contemplar la participación de la totalidad de los comuneros, desde los 14 años de edad en adelante, como se acostumbraba. Los antecedentes de Río Grande mencionan una vinculación entre el poblado y la producción minera desde la explotación de la mina prehispánica San Bartolo, sin embargo, según los autores del relato sobre la limpia, los hijos del pueblo que salieron a trabajar a los centros mineros y ciudades inmediatas - como Chuquicamata y Calama- establecieron diferencias en las responsabilidades comunitarias conforme a la cantidad de propie- 
dades que cada miembro de la comunidad comenzó a adquirir. Cabe referirse a que, justamente, en 1966, el presidente de la República, Eduardo Frei Montalva, promulgó la chilenización del cobre, acción que permitió la intervención chilena en la propiedad y dirección de la gran minería mediante la asociación al capital extranjero, proponiendo un aumento sustancial en la producción de este mineral a nivel nacional. En concordancia con los cambios económicos y sociales que estaban viviendo los riograndeños, en dicho año se llevó a cabo una asamblea especial en la que se acordó un nuevo sistema en base a tres ideas: «Todo propietario debe contratar o aportar con un peón, por cada bien que tenga. Aquél que carece de bienes o sea socio de la Junta de Vecinos, debe trabajar proporcionalmente al esfuerzo de un peón contratado. En caso de ser propietario de un solo bien puede trabajar él solamente, sin necesidad de contratar personal» (Lagos et ál. 1988: 54).

Más aún, el carácter voluntario de participación en la limpia dejará de serlo para pasar a ser obligatorio. Como se observa en el programa de la fiesta del año 2014, su citación es para el lunes 28 de julio a las 6:00, y se resalta con mayúsculas la obligatoriedad que tiene la actividad para todos los socios y propietarios (véase anexo 1). Si bien la naturaleza voluntaria por el bien común que alguna vez definió a las comunidades andinas se vio menguada por una nueva realidad socio-económica, es de destacar el hecho de que aún se siga realizando la ceremonia ritual en Río Grande. Esto, al considerar que ya en el año 1968, Lagos et ál. (1988: 44) aseguraban que en los poblados en que la canalización había sido reconstruida y tomada como responsabilidad de organismos estatales no se realizaba más la ceremonia de la limpia, «hecho que provoca en las personas mayores, lamentaciones de añoranzas por lo que ella significaba e implicaba para toda la comunidad. La limpia de canales es, además, la iniciación de fiestas ceremoniales en honor a la naturaleza» (Lagos et ál. 1988: 44). 
Los cambios relativos al número de habitantes en Río Grande y a los participantes en tiempos de fiesta no son exorbitantes, pero sí hablan de una constante en la disminución de pobladores. En 1971, según el relato de Lagos et ál. (1988: 47), la población de Río Grande era de 135 habitantes, sin embargo, en las festividades se reunían más de trescientas personas. En 1999, la población rural de Río Grande era cerca de 100 habitantes, triplicándose para las festividades (Castro et ál. 1999: 324). Hoy en día, según el censo del 2002, es un pueblo de 80 habitantes (INE 2002), que, para el tiempo festivo, según lo constatado en terreno, continúa recibiendo a más de trescientas personas. Los que llegan a la fiesta son en su mayoría jóvenes que viven en la ciudad, principalmente en Calama, al ubicarse a tan solo 51 kilómetros de distancia. Sus padres o abuelos son riograndeños, y la fiesta es el tiempo para visitarlos, para recordar y pedir por los ancestros, y para renovar energías para comenzar un nuevo ciclo.

Por otro lado, el «baile de los cuartos», que tanto impresionó en 1979 a Serracino y Barón, y que describieron como una de las ceremonias que, junto con el «teatro», marcaban la diferencia con las festividades de otros pueblos del interior de la provincia (Serracino y Barón 1979: 13), hoy en día se continúa realizando como parte de los ritos de la fiesta de Santiago, pero con algunas variaciones. El relato de Serracino y Barón sobre el baile de los cuartos es el siguiente:

La ceremonia de los cuartos consiste en que los pobladores regalen al Santo Patrón, ovejas, corderos y llamas. En la víspera de la fiesta se realiza un baile durante el cual se «cuartiliza» los animales (de allí el nombre de «cuartos»). Con la sangre se rocía la plaza y los cuatro puntos del pueblo. Después, en la «cera», se lleva en procesión hacia la iglesia los «cuartos», junto con otros productos de la tierra y velas y los dejan colgando en las andas de las imágenes. En día de la fiesta, cerca de las tres de la tarde, se sacan los «cuartos» y se forman parejas: dos hombres o dos mujeres; u hombre y mujer. Son seleccionados de las visitas. Las 
parejas en línea, se acercan a la puerta de la iglesia y entran. Se inclinan frente al santo y salen a la plaza por tres veces. Cada persona mantiene su «cuarto». Se repite, una vez, el mismo saludo en la plaza a la puerta de la iglesia. Después se gira alrededor de la plaza con los «cuartos» arriba en las manos. Se detienen frente a las cuatro «mesas de piedra» ubicadas en la plaza. Una vez que terminan estos saludos, que se hacen al «trote» acompañados por la música de la banda y de los sicus, se comienza a correr alrededor de la plaza; cada persona trata de partir en dos el «cuarto» que tiene en sus manos. Cuando cambia el ritmo de la música, se gira y se corre en sentido opuesto. Quien corta primero el «cuarto» tiene derecho a quedarse con él. Si se le cae, el «encargado» los azota con un pedazo de cuero. De vez en cuando se detienen y las señoras de pueblo sirven chicha, aloja y vino. La corrida de los «cuartos» dura hasta que todos hayan cortado su pedazo. A los últimos, y después de dos horas de correr, se les ayuda con un cuchillo.

Los cambios que podemos observar son, por ejemplo, que la ceremonia de los cuartos ya no se efectúa a las tres de la tarde, sino que se hace junto con la procesión del santo patrono. De hecho, el baile de los cuartos es el que da inicio a la procesión, las parejas sostienen las piernas de cordero, forman un túnel y al ritmo del trote van pasando por debajo de este. Además, el reparto de los cuartos se llevaría a cabo en la plaza el día posterior a Santiago Apóstol, alrededor de la 15:00, al finalizar la boda ofrecida por los alféreces tras la fiesta de santa Ana (véase anexo 1).

Se hace significativo notar que la participación de la comunidad en el baile de los cuartos ha ido perdiendo fuerzas. Según lo observado en la festividad del 2014, pasó un largo tiempo antes de que se conformaran las parejas, las cuales fueron incitadas una y otra vez por la familia de los alféreces. El poco interés existente en participar del baile puede tener las siguientes explicaciones: la primera guarda relación con que los jóvenes son los que pueden resistir, sin detener el ritmo del trote, cargar el cuarto de animal durante toda la procesión del santo patrono. Si se considera que, una vez 
terminada la fiesta de santa Ana, se llevan la pierna del animal a sus casas, ¿qué pasa cuando la mayoría vive en la ciudad y no cuentan con el traslado y el espacio necesario para su debida preparación? Por otro lado, tal como la alférez del siguiente año (2015) explicaba, desde la llegada de la iglesia evangélica a Río Grande, los pobladores se encuentran divididos y menos personas quieren participar de una festividad convocada por un santo católico. El templo evangélico, Iglesia Unida Pentecostal, se encuentra en el centro del pueblo muy próximo a la iglesia católica originaria de Río Grande. En la siguiente fotografía se muestra la procesión de Santiago Apóstol por las calles del pueblo, donde es posible observar la Iglesia Unida Pentecostal.

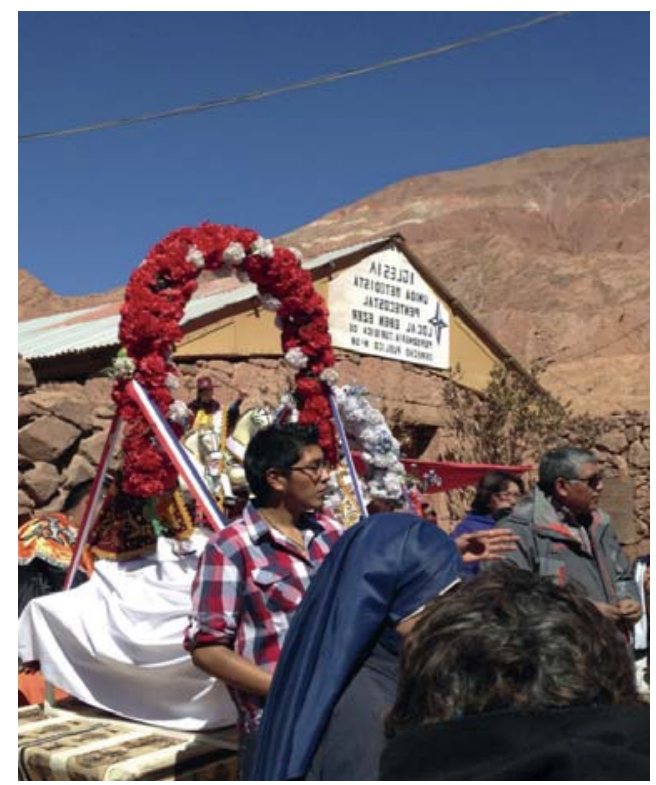

Santiago Apóstol y la Iglesia Unida Pentecostal.

Fotografía tomada por Bárbara Ossa durante la procesión de

Santiago Apóstol el 25 de julio del 2014. 
Finalmente, otro hecho cambiante, tiene relación con el rol de las mujeres y los hombres en las ceremonias y rituales del ciclo festivo. En la limpia de canales y acequias relatada por Lagos et ál. (1988: 50 y 52), son severamente establecidas y definidas las obligaciones y atributos de los Capitanes-Puricamanes hombres y mujeres, quienes son electos con el objeto de representar a su género en las tareas del rito comunitario. Según los autores, las obligaciones por género serían las siguientes:

Obligaciones particulares del Capitán-Puricamán de Hombres:

a) Todo lo que tenga relación a varones solamente.

b) Impone cumplimiento al Capitán Puricamán de Mujeres, para que sus representadas superen todo tipo de problema, permitiendo así la tranquilidad absoluta para que los hombres puedan realizar sus obligaciones.

c) Las órdenes debe darlas con debida anticipación, cerciorándose que cada uno de sus representados las haya recibido y entendido.

Obligaciones particulares del Capitán-Puricamán de Mujeres:

a) Se responsabiliza y representa a todas las mujeres.

b) Exige fiel cumplimiento de los deseos y peticiones de los maridos, hijos o peones de cada una, en la alimentación que se le haya pedido, puntualidad y participación en ceremonias y ritos.

c) Debe ayudar a las señoras si ellas lo requieren, e igualmente a los hombres, previa venia del Capitán.

d) Sus órdenes y peticiones debe efectuarlas con anticipación, procurando que todas las señoras las hayan entendido bien. 
En el programa del 2014 se señala que, en esta ocasión, los capitanes fueron mujeres: Cecilia Condori fue Capitán de los Hombres y Roberta Saire, de las Mujeres (véase anexo 1). La falta de público que participe activamente del ciclo festivo, como la llegada de nuevas mentalidades modernas y urbanas, podrían haber modificado las obligaciones que en el pasado restringían ciertas funciones solo para el género masculino y otras solo para el género femenino. Igualmente, es probable que las oportunidades laborales en la ciudad o en los centros mineros cercanos a Río Grande se adjudicaran principalmente a los hombres, mientras las mujeres permanecieron en el pueblo, adquiriendo mayor protagonismo en las actividades y responsabilidades dentro de las festividades.

Si bien la vinculación entre Río Grande y la minería se remonta a tiempos prehispánicos por su cercanía a la mina San Bartolo, a través de los relatos, podemos constatar un cambio notorio en la actividad económica y, en consecuencia, en los trabajos comunitarios de los riograndeños a partir de los años sesenta. De tal modo, la migración a la ciudad de una población joven en busca de oportunidades de trabajo, salud y educación tendrían una directa relación con los cambios evidenciados en el calendario del ciclo festivo. Y es que, esperar una semana desde el término de la fiesta del santo patrono, para recién iniciar la limpia de canales y acequias, ciertamente, nos traslada a una sociedad con un tiempo distinto al de la ciudad, en la que los días y las festividades son regidas por el respeto y el conocimiento de la Pachamama, y no por un calendario cívico estandarizado a nivel nacional. Año a año el ciclo festivo de Río Grande vive un proceso de aculturación, en el que elementos vinculados al mundo urbano y a la modernidad — como el que dos mujeres sean Capitanes-Puricamanes, el hecho de acortar el calendario festivo por razones prácticas, e incluso la llegada de los evangélicos al poblado — han transformado y resignificado la festividad en su estructura pero no en su fondo; conservando desde los primeros relatos de la fiesta, y seguramente desde tiempos ancestrales, la esencia basada en el diálogo, la tradición y la memoria. 


\section{Conclusiones}

Relato y memoria están fuertemente imbricados en las conclusiones que se han podido obtener de la investigación realizada en este trabajo. Buscamos adentrarnos en el ciclo festivo de la localidad de Santiago de Río Grande, para lo cual se hizo necesario situarlo y contextualizarlo. Fue a través de sus antecedentes, del uso polifónico de sus relatos y de la posibilidad de haber presenciado la fiesta de San Santiago que se pudo concluir que lo fundamental e inmutable en las tradiciones andinas de la actualidad es la relación de diálogo con la divinidad, expresada en ritos y signos que a lo largo del tiempo no han sufrido transformación alguna. Ahí están el baile de los cuartos, la noche de los abuelos, el pujgio para comunicarse con la divinidad, el respeto reverencial hacia los antepasados, entre otros. Pese al paso del tiempo y al avance de la modernidad, la relación dialógica con las divinidades se mantiene imperturbable. Es tal la importancia de este lazo que las transformaciones que ha sufrido el ciclo festivo - y que hemos podido evidenciar gracias al análisis de los relatos - sólo buscarían facilitar el acceso de mayor cantidad de personas oriundas del pueblo a este tipo de celebraciones, sin modificar el fondo de las ceremonias y ritos asociados. Por ello, es probable comprender que la adaptación a la realidad moderna es importante en la medida que facilita la conexión con la divinidad, eternizando así una tradición que arraiga los lazos con el pueblo y mantiene una identidad comunitaria.

Todo este tipo de análisis nos permite confirmar algo que asumimos tempranamente al momento de escribir este trabajo. Ambos autores asumimos que el relato era una importante fuente historiográfica por medio de la cual podíamos acceder a los distintos símbolos y concepciones antropológicas de lo que denominamos «ciclo festivo» de Santiago de Río Grande. Respaldamos dicha afirmación citando a Paul Ricoeur (2005: 31), quien ha señalado que en el relato confluye «una trama que funciona también como síntesis: 
fines, causas y azares se unen en la unidad temporal de una acción total y completa», resaltando de este modo el carácter temporal que este posee. En efecto, al articular las distintas experiencias, hechos o acontecimientos bajo un mismo significado, el relato desentraña la experiencia del tiempo del ser, y con ello permite que el tiempo, por medio de la agrupación de hechos, tenga un significado claro o, como diría Ricoeur, una «significación antropológica» (Ricoeur 2005: 24). Las implicancias de una significación antropológica del relato en relación al tiempo, y también la centralidad de este para el ser humano, convierten a esta fuente en un instrumento privilegiado para la Historia, disciplina que aborda la relación entre la temporalidad, lo espacial y lo humano, entre otras cosas. En consecuencia, un análisis acabado de los relatos es también un aporte a la comprensión del ser humano, sus rituales, su experiencia temporal y los significados con los que se relaciona o ha elaborado.

Frente a lo anterior, podemos señalar que los relatos son una fuente válida para analizar la historia y establecer observaciones que lleven a comprender los cambios y las continuidades que se manifiestan en forma elocuente a través de los ritos, signos y ceremonias que cada autor relataba. Sin haber comparado los relatos y la situación actual de Río Grande y sus festividades, difícilmente podríamos haber llegado a la conclusión de que, incluso en lo más sagrado de una comunidad, existe cambio, y el avance de la modernidad penetra hasta las más recónditas concepciones de lo humano y lo divino. Sin embargo, parece importante realizar este análisis desde una postura crítica, que permita reconocer las subjetividades e imprecisiones que se cuelan por medio de las fuentes utilizadas para abordar la fiesta de Santiago Apóstol y el ciclo en el que se encuentra inmersa. En este aspecto, los relatos utilizados fueron elocuentes al momento de vislumbrar ventajas y limitaciones en la utilización de esta fuente: algunos relatos fueron escritos por personas que habían vivido la fiesta durante muchos años en carne propia, lo que permitió analizar de mejor forma las distintas 
tradiciones que se llevan a cabo en este ciclo, como la noche de los abuelos, fiesta a la que el acceso es altamente restringido. Por otra parte, algunos relatos contenían imprecisiones temporales o repeticiones de hechos que nos confirmaron que su uso debía hacerse en forma crítica. ¿No es acaso la memoria similar en este aspecto? En palabras de Primo Levi:

La memoria humana es un instrumento maravilloso, pero falaz. Es una verdad sabida, y no solo por los psicólogos sino por cualquiera que haya dedicado alguna atención al comportamiento de los que lo rodean, o a su propio comportamiento. Los recuerdos que en nosotros yacen no están grabados sobre piedra; no solo tienden a borrarse con los años sino que, con frecuencia, se modifican o incluso aumentan literalmente, incorporando facetas extrañas. Lo saben muy bien los magistrados: casi nunca ocurre que dos testigos presenciales de un hecho lo describan del mismo modo y con las mismas palabras, aunque el suceso sea reciente y ninguno de los dos tenga interés en deformarlo.

En efecto, la memoria fue uno de los aspectos centrales que pudimos abordar en relación al ciclo de fiestas: la continuación de una memoria comunitaria trascendental en la localidad que es objeto de estudio ha permitido la continuación de una idiosincrasia y tradiciones andinas pese a diversas variaciones constatadas. Relacionamos esto con el relato y su origen primigenio, proveniente del latín relatus, que significa «hacer llevar» o «llevar consigo». En tal sentido, puede hacerse un parangón con lo más esencial de la memoria: esta última es traer algo al presente, poner en lo actual aquello que se vivió. Los relatos utilizados son ejercicios de las personas que lo escribieron para hacer presente algo que vivieron, ya sea la fiesta de Santiago Apóstol, la limpia de canales o la noche de los abuelos. En cada uno de los autores hubo un escudriñamiento en la memoria que permitió la escritura de una narración, cuyo espacio temporal y espacial puede estar afecto a características propias de la memoria, como la alteración en la sucesión de hechos. No obstante, 
la Historia se ha servido del relato y la memoria para la creación de interpretaciones históricas desde tiempos inmemoriales, y el fruto de esto - manifestado en esta investigación — viene a confirmar la validez de estos instrumentos para la creación histórica. En consecuencia, el binomio relato-memoria ha permitido comprender de mejor forma el mundo andino de Río Grande y, al mismo tiempo, reconocer las propuestas hechas en este estudio.

Existe otro vínculo importante que resaltar al momento de redactar los párrafos conclusivos de este trabajo: la memoria y el relato no pueden escapar de la temporalidad. De esa manera, se ha testificado que por medio del tiempo se produce una relación estrecha entre memoria, relato y tiempo: si la memoria es portar un recuerdo, y el relato porta la memoria de quienes han vivido algún hecho, las fuentes aquí utilizadas vuelven al presente. De eso se trata un relato: pone en el presente aquello que sucedió en el pasado. $\mathrm{Y}$ en este caso en particular, trae y resignifica para sus lectores actuales el tiempo festivo que hemos reconocido en la localidad de Río Grande. Coincidencia o no, tanto el relato como el tiempo festivo responden a una especie de temporalidad cíclica en la que la fiesta reinaugura un ciclo periódicamente, en este caso en honor a Santiago Apóstol y otros santos menores. El relato, en tanto, por medio de su lectura, trae el pasado al presente y rememora de este modo algo que ya pasó pero que vuelve a ocurrir al momento de ser leído. Ambas dinámicas rompen con el tiempo lineal y emergen en este en forma cíclica, lo que une memoria, relato y tiempo, historia y antropología, pasado y presente, fiesta y cotidianeidad.

Finalmente, viene a bien recordar las palabras del filósofo francés Paul Ricoeur que, en Tiempo y narración, menciona que el relato es «revelador, propio de su tiempo y del tiempo en el ser» (2005: 14). $\mathrm{Al}$ deshilvanar los relatos y comprender el tiempo en el que fueron escritos, y por medio de ello acceder al conocimiento del sujeto histórico y su contexto, pudimos otorgarle a la narración de hechos una significación antropológica y comprender así la importancia de rituales, ceremonias, signos y símbolos, al tiempo que se hicieron 
patentes los cambios y continuidades que cada escrito contenía. Esa significación antropológica hace posible historizar el «ciclo festivo» de Santiago de Río Grande por medio de las fuentes escogidas y con ello comprender e interpretar las huellas del pasado en el presente, labor propia de la Historia.

\section{Anexos}

Anexo 1. Transcripción textual del Programa 2014 de la fiesta de Santiago de Río Grande.

\section{Programa 2014}

Fiesta patronal de san Santiago de Río Grande

\section{Actividad}

Ronda Policial

Jefe de aseo

Jefe de bailes y músicos

Fabriquero

Jefe de cuartos

Jefe de imágenes

Altares y luminaria

Jefe de baños

Alféreces pasantes

Capitanes

Jefe de vehículos

Ayudante de turbina

\section{Responsable}

Directiva

Francisco Teran, Luis Saire (Plaza)

Francisco Condori

Felisa Anza, Bonifacio Anza, Juan Condor

Un bailarin por baile

Ivan Colque

Cecilia Condori

Encargado, Fresia Anza

Pascuala Anza (Baños Públicos Cobranza)

Elena Tito y Familia

Capitán de mujeres: Roberta Saire

Capitán de hombres: Cecilia Condori

La Directiva, Roberto Mondaca

Gladis Mendoza, Vicente Mendoza 
Martes 22 de julio de 2014

18:00 Hrs. Convivencia con los abuelos con toda la comunidad en la ramada del pueblo

21:00 Hrs. Incenciamiento de zampoñas en la ramada del pueblo

MiérColes 23 de JULIO DE 2014-11-27

5:00 Hrs. Ingreso de los bailes religiosos al pueblo por orden de llegada

7:00 Hrs. Alba ofresida por los alfereces [escrito a mano]

15:00 Hrs. Entrada de los alféreces en sector la Gruta

16:00 Hrs. Entrada de cera de San Santiago Aurora en la ramada del pueblo

20:00 Hrs. Víspera de San Santiago Aurora y luminaria en la iglesia del pueblo

Jueves 24 DE JULIO DE 2014

04:00 Hrs. Alba ofrecida por la alférez Elena Tito y familia en la plaza del pueblo

07:00 Hrs. Sacrificio del llamo blanco en la ramada del pueblo

10:00 Hrs. Misa de San Santiago Aurora y procesión

12:00 Hrs. Boda ofrecida por los alféreces pasantes

16:00 Hrs. Entrada a la cera de San Santiago Apóstol en la ramada del pueblo

21:00 Hrs. Misa con los bailes religiosos y la comunidad en la iglesia del pueblo

22:00 Hrs. Luminaria en las 4 esquinas a la espera del día 25 cumpleaños de San Santiago en la plaza del Pueblo

VIERNES 25 DE JULIO DE 2014

06:00 Hrs. Saludos a San Santiago con los bailes religiosos y la comunidad en la plaza del Pueblo y alba ofresida por los alfereses [escrito a mano]

10:00 Hrs. Izar el pabellón patrio en la plaza de la misa y comunidad y procesión en la plaza del Pueblo 
13:00 Hrs. Boda ofrecida por la alférez Elena Tito en la ramada del Pueblo

16:00 Hrs. Entrada de cera a Santa Ana en la ramada

21:00 Hrs. Víspera de Sana Ana en la plaza del Pueblo

SÁBAdo 26 DE JULIO DE 2014

09:00 Hrs. Misa rogativa de Santa Ana y procesión en la Gruta

12:00 Hrs. Comuneros (as) reciben a los capitanes en la plaza

12:30 Hrs. Despedida de los bailes religiosos en la iglesia

13:00 Hrs. Boda ofrecida por lo alféreces

15:00 Hrs. Reparto de los cuartos en la plaza

18:00 Hrs. Despedida de los bailes religiosos en la iglesia

19:00 Hrs. Ventilla en la plaza

20:00 Hrs. Luminaria de las 4 esquinas y control de leñas por el encargado del pueblo

Domingo 27 DE JULIO DE 2014

09:00 Hrs. Reunión general del Pueblo en la sede comunal

18:00 Hrs. Convivencia de los abuelos por la limpia de canal

Lunes 28 DE JULIO DE 2014

06:00 Hrs. Limpia de canal OBLIGATORIA de todos los socios y propietarios

21:00 Hrs. Caharpaya con los músicos del pueblo

Martes 29 de Julio de 2014

Término con incenciamiento de instrumentos de zampoñas

Firma

Hector Tito

Secretario
Firma

LUCAS CONDORI

Tesorero
Firma 


\section{REFERENCIAS}

Aldunate, Carlos, Victoria Castro y Varinia Varela

2008 «San Bartolo y Cobija: Testimonios de un modo de vida minera en las tierras altas y la costa de Atacama». Estudios Atacameños, Arqueologia y Antropología Surandinas, n. 35, pp. 97-118.

Bajtín, Mijaíl

1993 Problemas de la poética de Dostoievski. Buenos Aires: Brevarios del Fondo de Cultura Económica.

BERTRAND, Alejandro

1885 Memorias sobre las cordilleras del Desierto de Atacama i rejiones limitrofes: presentada al señor Ministro del Interior. Santiago: Imprenta Nacional.

FERnÁndeZ, Sergio

1979 Boletín de la Guerra del Pacífico 1879-1881. Santiago: Andrés Bello.

Cañete y Domínguez, Pedro Vicente

1939 Potosi colonial: Guía histórica, geográfica, física, política, civil y legal del gobierno e intendencia de la Provincia de Potosí. La Paz: Imp. Artística.

Cassasas Cantó, José María

1967 Noticias sobre la iglesia católica en la provincia de Antofagasta. Santiago: Orbe.

1974 Iglesias y capillas en la Región Atacameña. Antofagasta: Universidad del Norte.

Castro, Victoria

2009 De idolos a santos. Evangelización y religión andina en los Andes del sur. Santiago: Fondo de Publicaciones Americanistas, Universidad de Chile-Centro de Investigaciones Diego Barros Arana, DIBAM.

Castro, Victoria, Marcela Romo, Carolina Villagrán y Claudio Latorre

1999 «La transición entre las tradiciones de los oasis del desierto y de las quebradas altas del Loa superior: Etnobotánica del valle del Río Grande, 2. ${ }^{a}$ región, Chile». Chungará, vol. 31, n. 2, pp. 319-360. 
CAstro, Victoria, Varinia Varela, Carlos Aldunate y Edgardo Araneda 2004 «Principios orientadores y metodología para el estudio del QhapaqÑan en Atacama: Desde el portezuelo del inka hasta Río Grande». Chungará, vol. 36, n. 2, pp. 463-481.

Games, Larry y Cristián Games

2009 Iglesias atacameñas del altiplano chileno. Antofagasta: Ediciones universitarias, Universidad Católica del Norte de Antofagasta.

Gómez, Domingo, Carolina Gómez y Paulina Gómez

2013 Fiestas y ceremonias tradicionales andinas. Región de Antofagasta. Antofagasta: Biblioteca Cultura Popular.

Instituto Nacional de Estadísticas

2002 Censo. Publicación electrónica [en línea]: <http://www.ine.cl/ cd2002/> [Consulta: 15 de octubre de 2014].

Lagos, Reinaldo, Emilio Mendoza y Nolberto Ampuero

1982 «La Noche de los abuelos en Santiago de Río Grande». Chungará, n. 9, pp. 247-274.

Lagos, Reinaldo, Emilio Mendoza, Nolberto Ampuero y Nora Hernández

1988 «La limpia de canales y acequias de Santiago de Río Grande». Chungará, n. 21, pp. 43-78.

1997 «Aspectos rituales relacionados con el ganado en Santiago de Río Grande (II Región, Chile)». Estudios Atacameños, n. 12, pp. 105-124.

Levi, Primo

1989 Los hundidos y los salvados. Barcelona: Muchnik.

NúÑEz, Lautaro, José Antonio González y Claudio Galeno

2010 Rescate del patrimonio material más antiguo de la región: De las iglesias precordilleranas a los templos urbanos. Antofagasta: Ediciones Universitarias, Universidad Católica del Norte.

Pumarino, Héctor

1978 El Loa: Ayery hoy. Santiago: Editorial Universitaria. 
Ricoeur, Paul

2005 Tiempo y narración. México: Siglo XXI Editores.

RISO-PATRÓN, Luis

1910 La linea de la frontera con la República de Bolivia. Santiago: Sociedad Imprenta y Litografía Universo.

1918 «Diario de viaje a las cordilleras de Antofagasta y Bolivia (19031904)». Revista Chilena de Historia y Geografía, vol. 28, n. 31, pp. 152184.

1924 Diccionario jeográfico de Chile. Santiago: Imprenta Universitaria.

SAN Román, Francisco

1883 Desierto y cordilleras de Atacama. Santiago: Biblioteca Fundamentos de la Construcción de Chile.

SERracino, George y Ana María Barón

1979 «Santiago de Río Grande: Un tambo atacameño». Revista Tambo, año I, n. 3 .

Solano Astaburuaga y Cienfuegos, Francisco

1899 Diccionario Geográfico de la República de Chile. 2. ${ }^{\text {a }}$ edición, corregida y aumentada. Santiago: [s. n.].

SundT, Lorenzo

1909 Estudios Jeolójicos i Topográficos del Desierto i Puna de Atacama. Santiago: Sociedad Nacional de Minería.

VICUÑA, Manuel

1995 La imagen del desierto de Atacama (XVI-XIX): Del espacio de la disuasión al territorio de los desafíos. Santiago: Universidad de Santiago. 